\title{
Coordination of Ladyfinger Likeliness and Normal Breathing Rate
}

\author{
Muhammad Imran Qadir and Nazia Muneer* \\ Institute of Molecular Biology and Biotechnology, Pakistan \\ *Corresponding author: Nazia Muneer, Institute of Molecular Biology and Biotechnology, Pakistan
}

\begin{tabular}{ll}
\hline ARTICLE INFO & ABSTRACT \\
\hline
\end{tabular}

Received: 蔧 February 20, 2019

Published: 慧 March 05, 2019

Citation: Muhammad Imran Qadir, Nazia Muneer. Coordination of Ladyfinger Likeliness and Normal Breathing Rate. Biomed J Sci \& Tech Res 15(3)-2019. BJSTR. MS.ID.002709.

Keywords: Breathing Rate; Ladyfinger; Respiratory; Coordination
The ambition of the present course was to enhance the coordination of ladyfinger likeliness and normal breathing rate per minute. Breathing rate is the rate at which air is moving into and out of the lungs in one minute. Breathing rate is also called as respiratory rate or ventilation rate. The breathing cycle consists of inhalation and exhalation. Respiratory rate or breathing rate is the rate at which how many time we inhale or exhale air in one minute. The normal range for the breathing rate is 12 to 18 in one minute. There are two conditions of breathing i.e. over-breathing and under-breathing. Ladyfinger is used both as fruit and vegetable. It is grown in the well-drained are in the presence of sunlight. It is also used to treat the heartburn or pyrosis. It is also helpful in curing urinary problems. First of all we washed our hands with soap. Then we got the permission from the students that either we checked their breathing rate or not. Then we asked the student to lay down and relaxed him. We took the watch in other hand and said the student to breath and started counting down the number of breaths for one minute. After one minute we stopped the stop watch and recorded the readings. In the project designing, we made a Performa related to the coordination of ladyfinger likeliness and the normal breathing rate. 139 members coordinated with this study to which we asked about their normal breathing rate. These members were the post graduate students of University. It is obtained at the end that there is no coordination between the ladyfinger likeness and the normal breathing rate per minute.

\section{Introduction}

Breathing rate is the rate at which air is moving into and out of the lungs in one minute. Breathing rate is also called as respiratory rate or ventilation rate. It is measured in breaths per minute and is maintained by respiratory centre. In the breathing we inhale the oxygen into the lungs and exhale the carbon dioxide outside from the lungs. For all the aerobes oxygen is required for the respiration. This oxygen is then used to break down the foods for energy and carbon dioxide is removed as a waste products. The breathing cycle consists of inhalation and exhalation. In the inhalation, air is moved into the lungs from the outside. In the exhalation process, air or carbon dioxide is moved out of the lungs. The inhalation and exhalation are the repetitive processes. Respiratory rate or breathing rate is the rate at which how many time we inhale or exhale air in one minute. Breathing rate is the essential sign of life. The breathing rate is controlled by different homeostatic mechanisms. In this mechanism, partial pressure of oxygen and carbon dioxide is kept constant. There are two conditions of breathing i.e. over-breathing and under-breathing. The process in which the breathing rate is greater than the normal is called "over breathing or hyperventilation". While the process in which the breathing or respiratory rate is smaller than the normal breathing is "under-breathing or hypoventilation".

Breathing rate in the Homo sapiens is measured when the human is at rest or in relaxation state. During this we count the number of breathes that how many times the person's chest rises in one minute. The breathing rate is affected by different factors. It is different in different states means in case of fever or illness or in other condition it may raise. The breathing rate is measured by the stethoscope. The breathing rate measured by the stethoscope is larger than the breathing rate measured without the stethoscope beside the cot in children. The normal range for the breathing rate is 12 to 18 in one minute. This range is for the healthy adult which is taken at the rest condition. In the respiration, 2 seconds required for the inhalation and for exhalation three seconds needed. The breathing or respiratory rate is according to the age. In the babies, the breathing rate is 30 to 40 breathe in one minute. For three years 
child, the breathing rate is 20 to 30 breathe in one minute. For 6 years child, the respiratory rate is 18 to 25 in one minute. For the young breathing rate are 17 to 23 in a minute.

For adults, it ranges 12 to 18 in one minute. For elder whose age is 65 years or greater than 65 , breathing rate is 12 to 28 breaths per minutes. And for 80 or above 80 years elder, it is 10 to 30 breaths per minute.

The people whose oxygen saturation level is below 90 percent have higher respiratory rate. The other factors which influenced the breathing rate are age, agitation, crying and sleeping. The breathing rate is changed also by asthma, anxiety, heart failure, pneumonia, lung diseases or drugs overdose. When we take the overdose of medicine our breathing rate is affected [1]. Ladyfinger is used both as fruit and vegetable. It has pods which grow fastly within 60 days. After 60 days it is harvested. It is grown in the welldrained are in the presence of sunlight. For ladyfinger, soil $\mathrm{pH}$ is not important because it can grow in low acidic medium. Ladyfinger seed cannot germinate in the cold soil. So, it should not be grown in winter season. Though ladyfinger can tolerate the dry condition, but watering is important for its growth. For the okra, moisturing is necessary during the flowering and pod development.

In the okra plant, dietary fibres present which help in stabilizing the blood sugar. By the okra plant we can also minimize the cholesterol. When our cholesterol level is high, we can use ladyfinger to reduce the cholesterol because it keeps the cholesterol level stable. Okra plant also helps in reducing the heart diseases. For heart patients, okra works as a medicine to cure the disease. It also reduces the risks of cancer. For the ulcer patients, it is very helpful as an anti-ulcer. It is also used to treat the heartburn or pyrosis. It is also helpful in curing urinary problems. The ambition of the present course was to enhance the coordination of ladyfinger likeliness and normal breathing rate per minute [2].

\section{Material and Method}

The breathing is the process in which how many times man breaths in one minute. Breathing rate is measured by this procedure:

a) First of all, we washed our hands with soap. Then we got the permission from the students that either we checked their breathing rate or not. Then we asked the student to lay down and relaxed him. We took the watch in other hand and said the student to breath and started counting down the number of breaths for one minute. After one minute we stopped the stop watch and recorded the readings. We measured the breathing rate of other students in the same way. The normal breathing rate range is 12 to 20 per minute.

\section{Project Design}

In the project designing, we made a Performa related to the coordination of ladyfinger likeliness and the normal breathing rate. 139 members coordinated with this study to which we asked about their normal breathing rate. These members were the post graduate students of University.

\section{Statistical Analysis}

It was achieved by adopting software which is the M-State software. T-test was utilized to execute the result.

\section{Result and Discussion}

Coordination of ladyfinger likeliness and normal breathing rate was shown in the table. The average value and standard deviation values are calculated in this Table 1 . The table indicates that in case of men who like ladyfinger have mean value 23.43 with SD 5.20 and who don't like to have mean 20.5 with deviation 1.91 . The probability 0.06 which is smaller than 0.1 so it is significant. In case of women, who love ladyfinger have mean 19.76 with SD 4.73 and who do not like have mean value of 21.11 with standard deviation 5.33. The probability value obtained is 0.32 which is greater than 0.1 . When we talk about both men and women, those who love ladyfinger have mean 20.42 with deviation 5.00 and who do not have mean value of 21.0 with SD 4.86 . The probability value 0.61 is obtained which is greater than significant value 0.1 . So, we can say that there is no coordination between the ladyfinger likeliness and normal breathing rate. Questionnaire based studies have given an important advancement in recent researches [3-10]. There is no research on coordination of lady finger likeliness and normal breathing rate in the world.

Table 1: Coordination of ladyfinger likeliness and normal breathing rate.

\begin{tabular}{|c|c|c|c|}
\hline Gender & Likeliness & Dislikeness & $\begin{array}{c}\text { Probability- } \\
\text { value }\end{array}$ \\
\hline Men & $23.43 \pm 5.20$ & $20.5 \pm 1.91$ & 0.06 \\
\hline Women & $19.76 \pm 4.73$ & $21.11 \pm 5.33$ & 0.32 \\
\hline Combined & $20.42 \pm 5.00$ & $21 \pm 4.86$ & 0.61 \\
\hline
\end{tabular}

\section{Conclusion}

It is obtained at the end that there is no coordination between the ladyfinger likeness and the normal breathing rate per minute.

\section{References}

1. Qadir MI, Malik SA (2010) Comparison of alterations in red blood cell count and alterations in haemoglobin concentration in patients suffering from rectal carcinoma undergoing 5-fluorouracil and folic acid therapy. Pharmacology online 3: 240-243.

2. Qadir MI (2018) Rare \& uncommon diseases. Cambridge Scholars Publishing, England, pp. 168.

3. Qadir MI, Javid A (2018) Awareness about Crohn's Disease in biotechnology students. Glo Adv Res J Med Medical Sci 7(3): 062-064.

4. Qadir MI, Saleem A (2018) Awareness about ischemic heart disease in university biotechnology students. Glo Adv Res J Med Medical Sci 7(3): 059-061.

5. Qadir MI, Ishfaq S (2018) Awareness about hypertension in biology students. Int J Mod Pharma Res 7(2): 08-10.

6. Qadir MI, Mehwish (2018) Awareness about psoriasis disease. Int J Mod Pharma Res 7(2): 17-18.

7. Qadir MI, Shahzad R (2018) Awareness about obesity in postgraduate students of biotechnology. Int J Mod Pharma Res 7(2): 14-16. 
8. Qadir MI, Rizvi M (2018) Awareness about thalassemia in post graduate students. Lymphology \& Phlebology 2(1): 14-16.

9. Qadir MI, Ghalia BA (2018) Awareness survey about colorectal cancer in students of M. Phil Biotechnology at Bahauddin Zakariya University, Multan, Pakistan. Nov Appro in Can Study 1(3).

\section{ISSN: 2574-1241}

DOI: 10.26717/BJSTR.2019.15.002709

Nazia Muneer. Biomed J Sci \& Tech Res

This work is licensed under Creative Commons Attribution 4.0 License

Submission Link: https://biomedres.us/submit-manuscript.php
10. Qadir MI, Saba G (2018) Awareness about intestinal cancer in university student. Nov Appro in Can Study 1(3): NACS.000515.2018.

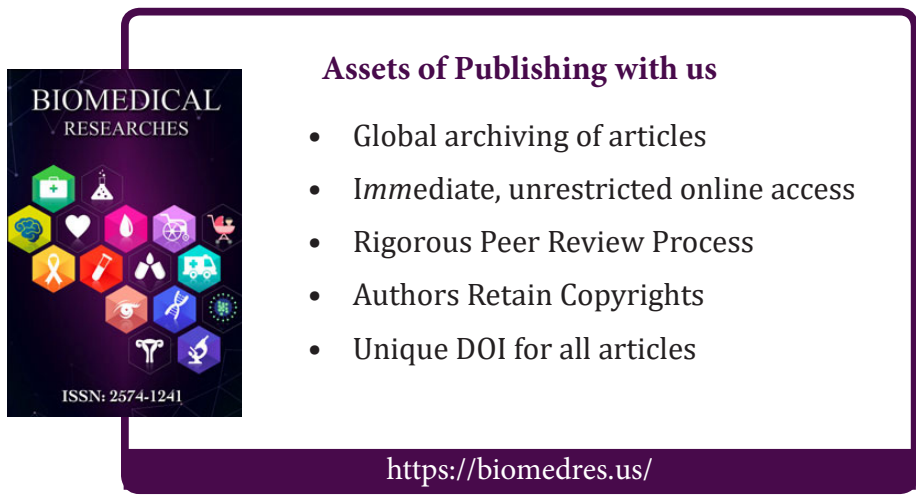

